\title{
Clinical results with two different pharmaceutical preparations of riboflavin in corneal cross-linking: an 18-month follow up
}

Hassan Hashemi ${ }^{1 *}$, Mohammad Amin Seyedian ${ }^{1}$, Mohammad Miraftab ${ }^{1}$, Hooman Bahrmandy ${ }^{1}$, Araz Sabzevari ${ }^{1}$ and Soheila Asgari

\begin{abstract}
Background: Comparison of long-term clinical results of two different pharmaceutical formulations used in corneal cross-linking (CXL) in keratoconus patients.

Methods: Sixty eyes of 60 keratoconus patients underwent CXL in two groups. We used riboflavin preparations from Sina Darou, Iran in group A, and Streuli Pharma, Switzerland in group B. Here we made inter-group comparison of changes in vision, refraction, Pentacam indices, corneal biomechanical indices, and endothelial cell count (ECC) 18 months after CXL.

Results: Since four patients were lost to follow-up, 56 eyes (28 eyes in each group) were compared. Mean improvement in uncorrected visual acuity (UCVA) was $0.31 \pm 0.65 \operatorname{LogMAR}(P=0.014)$ in group $A$ and $0.24 \pm 0.62 \operatorname{LogMAR}(P=0.082)$ in group $B$. Best corrected visual acuity $(B C V A)$ remained quite unchanged in both groups $(P=0.774)$. Mean spherical refractive error reduced by $0.45 \pm 1.15$ diopter $(D)(P=0.041)$ in group $A$ and $0.27 \pm 1.73 D(P=0.458)$ in group $B$ $(P=0.655)$. Cylinder error and spherical equivalent had a similar trend without any change. Max-K $(P=0.006)$ and mean-K $(P=0.044)$ decreased significantly more in group $A$ compared to group $B$. The reduction in CCT was significantly more in group $A$ than group $B(P=0.004)$. Q-value was quite unchanged in both groups $(P=0.704)$. The inter-group difference in $\mathrm{CH}$ reduction was borderline significant statistically $(P=0.057)$. Changes in corneal resistance factor and endothelial cell count were not significantly different between two groups $(P=0.117$ and $\mathrm{P}=0.229$ ).
\end{abstract}

Conclusion: Clinical results of CXL with the domestic preparation of riboflavin are similar to that achieved with the Swiss made product in some aspects, and it is the preferred brand in some other aspects. This study will continue to report longer follow-up results.

Trial registration: IRCT201212034333N2

Keywords: Keratoconus, Cross linking, Riboflavin, Sina Darou, Streuli Pharma, Clinical trial

\section{Background}

Collagen cross linking with riboflavin (CXL) was first developed by Wollensak et al. [1] to stop the progression of keratoconus. In this procedure, riboflavin plays an important role because it absorbs UVA and it reduces cell damage [1]. The riboflavin preparation used in Iran is a product of Streuli Pharma, a Swiss company. Export

\footnotetext{
* Correspondence: hhashemi@norc.ac.ir

${ }^{1}$ Noor Ophthalmology Research Center, Noor Eye Hospital, No. 96 Esfandiar Blvd., Vali'asr Ave, Tehran, Iran

Full list of author information is available at the end of the article
}

company of Sina Darou has manufactured this product in Iran with the same formulation and amount of active substance as the Swiss equivalent, and we have studied its clinical results in patients treated with CXL. In the preliminary report [2], we demonstrated that 6-month changes in vision, refraction, K-reading, corneal biomechanics, and endothelial cell count parameters were not significantly different between the two groups, and clinical results achieved with these formulations are similar. Here we compare 18-month results between these two 
preparations, so that we can comment on their clinical use with better certainty.

\section{Methods}

The complete study methodology has previously been described [2]. In brief, we enrolled 60 eyes of 60 keratoconus patients (30 eyes in each group) in this parallel non-randomized clinical trial. The Iranian preparation of riboflavin 0.1\% (Sina Darou, Iran) was used in the first group (group A), and the Swiss preparation of riboflavin 0.1\% (Streuli Pharma, Uznach, Switzerland) was used in the second group (group B) during the procedure. Inclusion criteria were the diagnosis of progressive keratoconus on clinical exam which is confirmed paraclinically, age between 15 and 35 years, keratometry less than 55.0 diopter (D), and a minimum central corneal thickness (CCT) of 400 microns $(\mu \mathrm{m})$.

First the study methods and objectives were explained to the subjects, and they were enrolled in the study after obtaining written informed consents. The study was approved by Noor Review Board. Iranian Registry of Clinical Trials also approved the study (registration number: IRCT201212034333N2).

The surgical procedure has already been described [3]. After local anesthesia, 3 or 4 strips 2 millimeter wide, and about 1 millimeter apart were removed from the central 7 millimeter of the cornea, leaving the corneal epithelial intact in-between. Another epithelium strip was removed horizontally from the inferior third of the cornea. Then, riboflavin $0.1 \%$ drops in $20 \%$ dextran were instilled onto the corneal surface for half an hour at 3 minute intervals. After ensuring of the presence of riboflavin and observing a yellow Tyndall effect in the anterior chamber, irradiation at a wavelength of 370 nanometer and power of $3 \mathrm{~mW} / \mathrm{cm}^{2}$ was commenced from a distance of $5 \mathrm{~cm}$. Irradiation was done using the UVX system (IROC, Zürich, Switzerland). Riboflavin instillation continued every three minutes during the 30 minutes of irradiation. At the end of this stage, the corneal surface was rinsed with sterile balanced saline solution, a soft bandage contact lens (Night \& Day, Ciba Vision, Duluth, GA) was applied, and chloramphenicol $0.5 \%$ eye drop was instilled. Postoperative medication included chloramphenicol $0.5 \%$ eye drops four times daily, betamethasone $0.1 \%$, and preservative free artificial tears (Hypromelose) as required. Patients were examined on day 1 and 3 after the procedure, and the lens was removed the epithelium had healed. After removing the lens, chloramphenicol was discontinued, and betamethasone was continued twice daily for another week. When the epithelium was not healed, daily visits were continued until complete healing. No case of intraoperative or postoperative complication was observed.

Paraclinical tests included the assessment of uncorrected and best spectacle corrected visual acuity (UCVA and BCVA) using the Snellen chart, and determining the spherical equivalent (SE) using a Retinoscope (HEINE BETA 200, Germany). We also checked corneal topographic indices using Pentacam (Oculus Optikgerate GmbH, Germany), corneal biomechanical parameters using the Ocular Response Analyzer (ORA; Reichert Ophthalmic Instruments, Buffalo, USA), and the endothelial cell count (ECC) with a non-contact specular microscope (Konan Medical, Hyogo, Japan).

The trend of changes was compared between the two groups using repeated measures analysis of variance, and intra-group differences between before and 18 months after the procedure was assessed using the paired $t$ test. We chose a significance level of 0.05 .

\section{Results}

Since 2 patients from each group did not show up on the 18 month follow-up exam, 56 eyes of 56 keratoconus patients treated with CXL (28 eyes in each group) were compared. Their mean age was $24.32 \pm 4.59$ years, and $65 \%$ were male. Patients were treated with Iranian riboflavin (group A) and Swiss riboflavin (group B) in two groups of 28 people. Since the study had a nonrandomized approach, preoperative values of all parameters were compared between the two groups, and there was no significant difference in any case.

At 18 months, mean UCVA improved similarly $(\mathrm{P}=$ $0.684)$ by $0.31 \pm 0.65 \operatorname{LogMAR}(\mathrm{P}=0.014)$ in group $\mathrm{A}$ and $0.24 \pm 0.62 \operatorname{LogMAR}(\mathrm{P}=0.082)$ in group $\mathrm{B}$. BCVA remained unchanged in both groups $(\mathrm{P}=0.774)$. Mean spherical refractive error reduced by $0.45 \pm 1.15 \mathrm{D}(\mathrm{P}=$ $0.041)$ in group $\mathrm{A}$ and $0.27 \pm 1.73 \mathrm{D}(\mathrm{P}=0.458)$ in group $\mathrm{B}(\mathrm{P}=0.655)$. Cylinder error and spherical equivalent had a similar trend without any change (Table 1).

Despite similar 6 month trends between the two groups, the 18-month decrease in max- $\mathrm{K}$ was $1.44 \pm 1.31$ $\mathrm{D}(\mathrm{P}<0.001)$ in group $\mathrm{A}$ and $0.52 \pm 0.82 \mathrm{D}(\mathrm{P}=0.007)$ in group $\mathrm{B}$, and the inter-group difference in was statistically significant in this regard $(P=0.006)$. Mean- $K$ decrease was $1.33 \pm 1.19(\mathrm{P}<0.001)$ and $0.69 \pm 1.00(\mathrm{P}=$ $0.004)$ in groups $A$ and $B$, respectively; the difference was statistically significant $(P=0.044)$. CCT decreased significantly more $(\mathrm{P}=0.004)$ in group A $(47.00 \pm$ $33.10 \mu \mathrm{m}, \mathrm{P}<0.001)$ than group $\mathrm{B}(22.32 \pm 20.87 \mu \mathrm{m}$, $\mathrm{P}<0.001$ ). Q-value remained quite unchanged in group $\mathrm{A}$ and became slightly prolate in group $\mathrm{B}$; the inter-group difference was not statistically significant $(P=0.704)$ (Table 2).

The inter-group difference in corneal hysteresis $(\mathrm{CH})$ decrease was borderline significant $(\mathrm{P}=0.062)$. Corneal resistance factor (CRF) decrease was not significantly different between the two groups $(P=0.242)$. Mean ECC decreased similarly in both groups $(\mathrm{P}=0.598)$ (Table 3). 
Table 1 Trend of changes in vision and refraction parameters in the two groups of keratoconus patients treated with Iranian and Swiss preparations of riboflavin

\begin{tabular}{|c|c|c|c|c|c|c|c|}
\hline & Riboflavin & No of eyes & Pre operation & $\begin{array}{l}6 \text { months } \\
\text { after surgery }\end{array}$ & $\begin{array}{l}18 \text { months } \\
\text { after surgery }\end{array}$ & P-value ${ }^{*}$ & P-value ** \\
\hline \multirow[t]{2}{*}{ UCVA (logMAR) } & Sina Darou, Iran & 28 & $0.77 \pm 0.66$ & $0.45 \pm 0.36$ & $0.44 \pm 0.41$ & 0.014 & 0.684 \\
\hline & Streuli Pharma, Switzerland & 28 & $0.89 \pm 0.56$ & $0.79 \pm 0.53$ & $0.66 \pm .47$ & 0.082 & \\
\hline \multirow[t]{2}{*}{ BCVA (logMAR) } & Sina Darou, Iran & 28 & $0.20 \pm 0.19$ & $0.19 \pm 0.13$ & $0.17 \pm 0.13$ & 0.710 & 0.774 \\
\hline & Streuli Pharma, Switzerland & 28 & $0.22 \pm 0.20$ & $0.20 \pm 0.23$ & $0.22 \pm 0.22$ & 0.880 & \\
\hline \multirow[t]{2}{*}{ Sphere (diopter) } & Sina Darou, Iran & 28 & $-1.36 \pm 2.18$ & $-1.42 \pm 2.36$ & $-1.15 \pm 2.25$ & 0.041 & 0.655 \\
\hline & Streuli Pharma, Switzerland & 28 & $-1.69 \pm 1.92$ & $-1.73 \pm 2.48$ & $-1.59 \pm 2.69$ & 0.458 & \\
\hline \multirow[t]{2}{*}{ Cylinder (diopter) } & Sina Darou, Iran & 28 & $-2.67 \pm 1.83$ & $-2.36 \pm 1.79$ & $-2.40 \pm 1.77$ & 0.827 & 0.642 \\
\hline & Streuli Pharma, Switzerland & 28 & $-2.64 \pm 1.91$ & $-2.95 \pm 1.97$ & $-2.33 \pm 2.16$ & 0.332 & \\
\hline \multirow[t]{2}{*}{ Spherical equivalent (diopter) } & Sina Darou, Iran & 28 & $-2.69 \pm 2.44$ & $-2.60 \pm 2.85$ & $-2.35 \pm 2.52$ & 0.093 & 0.875 \\
\hline & Streuli Pharma, Switzerland & 28 & $-3.01 \pm 2.29$ & $-3.20 \pm 2.80$ & $-2.76 \pm 3.12$ & 0.230 & \\
\hline
\end{tabular}

*Intra-group comparison of parameters before and 18 months after the procedure using paired $t$ test.

**Inter-group comparison of parameters' trend of changes using repeated measures ANOVA.

\section{Discussion}

CXL slows down or halts the progression of keratoconus by forming covalent bonds in the corneal stroma that are created as an effect of free radicals. In this process, UV-irradiated riboflavin produces free radicals, and riboflavin concentration influences the level of UV absorption and strengthening reactions in the cornea. In-vivo, riboflavin can increase UV absorption up to 95\% [4]. This is while UV absorption in the cornea is only $25-35 \%$ without riboflavin [5]. With riboflavin concentrations between 0 to $0.04 \%$, UV absorption increases linearly, but has no further effect [6]. Thus, using riboflavin is one of the main pillars of the treatment.

In the 6-month report [2], we compared preliminary clinical results of treatment with Iranian and Swiss preparations of riboflavin which demonstrated the effectiveness of the Iranian preparation. Six-month changes in vision, refraction, corneal topographic and biomechanical parameters, and ECC were similar in the two groups, and no inter-group difference was found. Clinical parameters were not significantly different at 18 months either, and both preparations were similar in terms of stopping the progression of keratoconus. The two preparations were only different in terms of corneal topographic indices; better flattening was achieved with the Iranian preparation while CCT decrease was less with the Swiss product. It must be noted, however, that this study was nonrandomized, and to lessen the effect of this limitation, we performed matching using base indices.

Stability of vision and refraction parameters in the group treated with Sina Darou riboflavin indicated that disease progression had stopped. Various results have been reported after treatment with CXL. Some studies demonstrated no change $[2,7,8]$, some observed improvement [8-10], and some showed reduced vision and increased refraction [7]. This can be due to inter-study differences in preoperative values or disease severity in the study samples. Different corneal structures in different populations can be another reason that causes such differences. Another point is that vision assessment is a

Table 2 Trend of changes in parameters measured with Pentacam compared between two groups of keratoconic patients treated with Iranian vs. Swiss preparations of riboflavin

\begin{tabular}{|c|c|c|c|c|c|c|c|}
\hline & Riboflavin & No of eyes & Pre operation & $\begin{array}{l}6 \text { months } \\
\text { after surgery }\end{array}$ & $\begin{array}{l}18 \text { months } \\
\text { after surgery }\end{array}$ & P-value ${ }^{*}$ & P-value ${ }^{* *}$ \\
\hline \multirow[t]{2}{*}{ Maximum keratometry (Diopter) } & Sina Darou, Iran & 28 & $49.05 \pm 3.57$ & $48.45 \pm 2.79$ & $47.74 \pm 3.76$ & $<0.001$ & 0.006 \\
\hline & Streuli Pharma, Switzerland & 28 & $48.60 \pm 3.33$ & $48.74 \pm 3.56$ & $48.06 \pm 3.16$ & 0.007 & \\
\hline \multirow[t]{2}{*}{ Mean keratometry (Dipoter) } & Sina Darou, Iran & 28 & $47.14 \pm 3.37$ & $46.37 \pm 2.30$ & $45.98 \pm 3.78$ & $<0.001$ & 0.044 \\
\hline & Streuli Pharma, Switzerland & 28 & $47.07 \pm 2.91$ & $47.00 \pm 3.21$ & $46.37 \pm 3.00$ & 0.004 & \\
\hline \multirow[t]{2}{*}{ Q-value } & Sina Darou, Iran & 28 & $-0.69 \pm 0.38$ & $-0.68 \pm 0.39$ & $-0.68 \pm 0.57$ & 0.651 & 0.704 \\
\hline & Streuli Pharma, Switzerland & 28 & $-0.72 \pm 0.33$ & $-0.75 \pm 0.45$ & $-0.63 \pm 0.38$ & 0.064 & \\
\hline \multirow[t]{2}{*}{ Central corneal thickness $(\mu \mathrm{m})$} & Sina Darou, Iran & 28 & $482.1 \pm 29.7$ & $467.5 \pm 29.8$ & $441.5 \pm 45.0$ & $<0.001$ & 0.004 \\
\hline & Streuli Pharma, Switzerland & 28 & $496.9 \pm 35.6$ & $481.5 \pm 37.3$ & $474.7 \pm 41.2$ & $<0.001$ & \\
\hline
\end{tabular}

*Intra-group comparison of parameters before and 18 months after the procedure using paired t test.

**Inter-group comparison of parameters' trend of changes using repeated measures ANOVA. 
Table 3 Trend of changes in corneal biomechanical parameters and endothelial cell count compared between two groups of keratoconic patients treated with Iranian vs. Swiss preparations of riboflavin

\begin{tabular}{|c|c|c|c|c|c|c|c|}
\hline & Riboflavin & No of eyes & Pre operation & $\begin{array}{l}6 \text { months } \\
\text { after surgery }\end{array}$ & $\begin{array}{l}18 \text { months } \\
\text { after surgery }\end{array}$ & P-value ${ }^{*}$ & P-value ${ }^{* *}$ \\
\hline \multirow[t]{2}{*}{ Corneal hysteresis $(\mathrm{mmHg})$} & Sina Darou, Iran & 28 & $7.67 \pm 1.44$ & $6.69 \pm 1.52$ & $6.44 \pm 1.37$ & $<0.001$ & 0.062 \\
\hline & Streuli Pharma, Switzerland & 28 & $7.63 \pm 2.12$ & $7.36 \pm 1.50$ & $7.53 \pm 1.66$ & 0.701 & \\
\hline \multirow[t]{2}{*}{ Corneal resistance factor $(\mathrm{mmHg})$} & Sina Darou, Iran & 28 & $6.74 \pm 1.66$ & $6.20 \pm 1.24$ & $5.88 \pm 1.93$ & 0.023 & 0.242 \\
\hline & Streuli Pharma, Switzerland & 28 & $6.94 \pm 1.97$ & $6.94 \pm 1.74$ & $6.79 \pm 1.90$ & 0.716 & \\
\hline \multirow[t]{2}{*}{ Endothelial cell count (cell/mm²) } & Sina Darou, Iran & 28 & $2789.3 \pm 160.8$ & $2455.4 \pm 312.9$ & $2511.7 \pm 271.8$ & $<0.001$ & 0.176 \\
\hline & Streuli Pharma, Switzerland & 28 & $2731.6 \pm 262.9$ & $2470.7 \pm 274.1$ & $2574.9 \pm 305.5$ & $<0.001$ & \\
\hline
\end{tabular}

*Intra-group comparison of parameters before and 18 months after the procedure using paired t test.

**Inter-group comparison of parameters' trend of changes using repeated measures ANOVA.

subjective test which can be influenced by environmental conditions, optometrists' accuracy, and patients' condition. Thus, diverse results can be expected.

Corneal topographic changes were significantly different between the two groups. Although both groups demonstrated a significantly reduced protrusion and decreased CCT, patients achieved better corneal flattening when treated with Iranian riboflavin. The reduction in corneal thickness, however, was less in the group of patients treated with Swiss riboflavin. This could imply better intra-fibril bond formation is supported by the Iranian preparation due to better UVA absorption, and thus, keratometry is decreased. The lack of significant inter-group difference in ECC showed that despite better UV absorption, cytotoxic effects were not intensified, and there was no keratocyte loss $[11,12]$. Some studied have demonstrated reduced corneal thickness despite reduced keratometry and halted disease progression [13-15], and this has mostly been attributed to stages of epithelium removal and riboflavin instillation [16].

CRF reduction was similar in the two groups. The inter-group difference in $\mathrm{CH}$ reduction was borderline significant $(\mathrm{P}=0.062)$. However, $\mathrm{CH}$ and $\mathrm{CRF}$ are not enough to show changes in corneal biomechanical properties [17], we would need to examine other indices measured with ORA to have a more accurate assessment of the effects of these two preparations.

\section{Conclusion}

Finally, based on 18-month results, apart from better flattening with the Iranian preparation and better maintenance of corneal thickness with the Swiss product, cresults in terms of clinical vision, refraction, biomechanical properties, and the endothelial cell count were comparable with these two types preparations of riboflavin. We can thus conclude that the Iranian riboflavin (Sina Darou) can be an alternative for its Swiss counterpart in CXL. This study will continue to assess the stability of results at later follow-ups.

\section{Abbreviations}

CXL: Corneal cross linking; SE: Spherical equivalent; BCVA: Best corrected visual acuity; UCVA: Uncorrected visual acuity; max K: Maximum keratometry; CCT: Central corneal thickness; ECC: Endothelial cell count; CH: Corneal hysteresis; CRF: Corneal resistance factor.

\section{Competing interests}

The authors declare that they have no competing interests.

\section{Authors' contributions}

$\mathrm{HH}$ has designed and supervised the project. MA, MM and HB performed the surgeries. AS and SA analyzed and interpreted the data and wrote the manuscript. HH, MA, MM and HB finalized the manuscript. All authors read and approved the final manuscript.

\section{Author details}

${ }^{1}$ Noor Ophthalmology Research Center, Noor Eye Hospital, No. 96 Esfandiar Blvd., Vali'asr Ave, Tehran, Iran. ${ }^{2}$ Department of Epidemiology and Biostatistics, School of Public Health, Tehran University of Medical Sciences, International Campus (TUMS-IC), Tehran, Iran.

Received: 21 October 2014 Accepted: 4 January 2015

Published online: 24 January 2015

\section{References}

1. Wollensak G, Spoerl E, Seiler T. Riboflavin/ultraviolet-a-induced collagen crosslinking for the treatment of keratoconus. Am J Ophthalmol. 2003;135:620-7.

2. Hashemi H, Seyedian MA, Miraftab M, Bahrmandy H, Sabzevari A, Asgari S. Comparison of clinical results of two pharmaceutical products of riboflavin in corneal collagen cross-linking for keratoconus. Daru: J Faculty Pharm, Tehran Univ Med Sci. 2014;22:37.

3. Hashemi H, Seyedian MA, Miraftab M, Fotouhi A, Asgari S. Corneal Collagen Cross-linking with Riboflavin and Ultraviolet A Irradiation for Keratoconus: Long-term Results. Ophthalmology. 2013;120:1515-20.

4. Sporl E, Schreiber J, Hellmund K, Seiler T, Knuschke P. Studies on the stabilization of the cornea in rabbits. Ophthalmologe. 2000;97:203-6.

5. Tsubai T, Matsuo M. Ultraviolet light-induced changes in the glucose-6-phosphate dehydrogenase activity of porcine corneas. Cornea. 2002;21:495-500.

6. Spoerl E, Mrochen M, Sliney D, Trokel S, Seiler T. Safety of UVA-riboflavin cross-linking of the cornea. Cornea. 2007;26:385-9.

7. Asri D, Touboul D, Fournie P, Malet F, Garra C, Gallois A, et al. Corneal collagen crosslinking in progressive keratoconus: multicenter results from the French National Reference Center for Keratoconus. J Cataract Refract Surg. 2011;37:2137-43.

8. Goldich Y, Marcovich AL, Barkana Y, Mandel Y, Hirsh A, Morad Y, et al. Clinical and Corneal Biomechanical Changes After Collagen Cross-Linking With Riboflavin and UV Irradiation in Patients With Progressive Keratoconus: Results After 2 Years of Follow-up. Cornea. 2012;31:609-14. 
9. Henriquez MA, Izquierdo Jr L, Bernilla C, Zakrzewski PA, Mannis M. Riboflavin/Ultraviolet A corneal collagen cross-linking for the treatment of keratoconus: visual outcomes and Scheimpflug analysis. Cornea. 2011;30:281-6.

10. Hersh PS, Greenstein SA, Fry KL. Corneal collagen crosslinking for keratoconus and corneal ectasia: One-year results. J Cataract Refract Surg. 2011;37:149-60.

11. Wollensak G, Spoerl E, Reber F, Seiler T. Keratocyte cytotoxicity of riboflavin/UVA-treatment in vitro. Eye (Lond). 2004;18:718-22.

12. Wollensak G, Spoerl E, Seiler T. Stress-strain measurements of human and porcine corneas after riboflavin-ultraviolet-A-induced cross-linking. J Cataract Refract Surg. 2003;29:1780-5.

13. Cinar $Y$, Cingu AK, Turkcu FM, Cinar T, Yuksel H, Ozkurt ZG, et al. Comparison of accelerated and conventional corneal collagen cross-linking for progressive keratoconus. Cutan Ocul Toxicol. 2014;33:218-22.

14. Saffarian L, Khakshoor H, Zarei-Ghanavati M, Esmaily H. Corneal Crosslinking for Keratoconus in Iranian Patients: Outcomes at 1 year following treatment. Middle East Afr J Ophthalmol. 2010;17:365-8.

15. Kanellopoulos AJ, Asimellis G. Keratoconus management: long-term stability of topography-guided normalization combined with high-fluence $C X L$ stabilization (the Athens Protocol). J Refract Surg. 2014;30:88-93.

16. Kymionis GD, Kounis GA, Portaliou DM, Grentzelos MA, Karavitaki AE, Coskunseven $\mathrm{E}$, et al. Intraoperative pachymetric measurements during corneal collagen cross-linking with riboflavin and ultraviolet A irradiation. Ophthalmology. 2009;116:2336-9.

17. Hallahan KM, Sinha Roy A, Ambrosio Jr R, Salomao M, Dupps Jr WJ. Discriminant value of custom ocular response analyzer waveform derivatives in keratoconus. Ophthalmology. 2014;121:459-68.

\section{Submit your next manuscript to BioMed Central and take full advantage of:}

- Convenient online submission

- Thorough peer review

- No space constraints or color figure charges

- Immediate publication on acceptance

- Inclusion in PubMed, CAS, Scopus and Google Scholar

- Research which is freely available for redistribution 